\title{
Pedro García y el color del vidrio
}

\author{
M. a Teresa González Vicario *
}

RESUMEN

El vidrio es uno de los materiales que ha alcanzado una dimensión escultórica en el siglo xx. Fue a mediados de este siglo, aproximadamente, cuando tuvo lugar su incorporación a la escultura contemporánea, y aunque España se ha sumado con un cierto retraso a esta nueva vertiente del lengueje escultórico, no son pocos los nombres de escultores que podrian ser citados por haber descubierto las posibilidades que el vidrio encierra como material escultórico.

Uno de ellos es Pedro García, quien ha encontrado en el vidrio laminado, un material de procedencia industrial, su medio de expresión plástica. El análisis de su evolución artística hasta el momento actual constituye el objeto de este articulo,

para lo cual se ha partido de unas primeras obras que obedecen a un planteamiento constructivo, racionalista, $y$ en las que el vidrio ha sido trabajado en frío. Pero sin abandonar esta técnica, Pedro García se inclina posteriormente por unas soluciones que

\section{ABSTRACT}

The apparition of glass as a new material in sculpture dates from the middle of the XXth century. Spain has incorporated the sculptoric possibilities of glass later than other countries, but it has had an important following by an important group of sculptors. One of them is Pedro Garcia, who has found in laminated glass, an industrial type of glass, his chief inspiration. This article traces the history of his artistic evolution. In the beginning his sculptures were very constructive and rational. Later, he developed a special technique working on glass in the process of formation through heat

\footnotetext{
* Departamento de Historia del Arte. UNED.
} 
suponen la utilización del vidrio termoformado. Este procedimiento técnico permite explorar los efectos ópticos del color al incluir entre las láminas de vidrio sustancias orgánicas

para conseguir determinados

pigmentos que se suman a otros colorantes químicos. El vidrio laminado se transforma asi en una materia que no busca la pureza y se complace en lo irregular, en lo asimétrico y en el contraste de texturas. (thermoformated). This enabled him to incorporate colour and organic substances to his work. In his sculptures laminated glass becomes a material where purity is not the issue as much as contrast of textures and irregular, asimetric forms.

La radical transformación experimentada por la escultura en el siglo $x x$ ha supuesto, entre otros cambios, la utilización de materiales nuevos. Sin embargo, en determinados casos sería más conveniente referirse a un nuevo descubrimiento, como sucede con el hierro y el vidrio, debido a que su empleo en el terreno escultórico es todavía muy reciente, al margen de haber sido usados desde hace siglos con una finalidad artística y también práctica. La nueva dimensión alcanzada por los materiales en el siglo $x x$ fue señalada, entre otros artistas, por Boccioni al afirmar que es preciso "destruir la pretendida nobleza -muy literaria y tradicional- del mármol y del bronce, y negar radicalmente que haya que servirse de una sola materia para un conjunto escultórico. El escultor puede emplear veinte materias distintas, o incluso más en una sola obra, siempre que lo exija la emoción plástica. He aquí una pequeña parte de esta variedad de materias: vidrio, madera, cartón, cemento, hormigón, crin, cuero, tela, espejos, luz eléctrica, etc..." '. De igual forma, Kandinsky defendió la necesidad de utilizar "todo material, desde el más consistente hasta el que sólo existe en abstracción bidimensional como elemento de la forma»? Con estas afirmaciones, tanto Boccioni como Kandinsky estaban reivindicando para el arte del siglo xx la total libertad en el uso de los materiales.

Uno de los que ha alcanzado una dimensión plenamente escultórica es el vidrio. Desde su lejano descubrimiento en Oriente Medio, este material, obtenido de la fusión de elementos vitrificantes, fundentes y estabilizantes - sílice, álcalis y cal- ha tenido diversas aplicaciones, siendo muy relevante entre ellas el arte de la vidriera. Pero fue a mediados de este siglo, aproximadamente, cuando surgieron unos planteamientos innovadores que confirieron al

Boccioni, U.: "Technical Manifesto of Futurist Sculpture 1912» en Apoltonio, U.(Ed.): Futurist Manifestos. London, Thames and Hudson, 1973, pág. 65.

KanDINSkY, W.: "Über die Formfrage" en Der Blaue Reiter. Munich, 1912. 
vidrio su dimensión plenamente escultórica, una dimensión que ha supuesto la valoración de su fragilidad (fig. 1) y, al mismo tiempo, de su resistencia (fig. 2), sin olvidar la opacidad (fig. 3) y, a la vez, la transparencia (fig. 4) de una materia cuyo poder de refracción origina una variedad de juegos ópticos. En este sentido, Vera Lisková (Praga, R.S. Checa, 1924-1985), Luciano Vistosi (Murano, Italia, 1931), Stephen Procter (Sussex, G. Bretaña, 1946) y Colin Reid (Cheschire, G. Bretaña, 1953) respectivamente nos ofrecen unos ejemplos muy elocuentes en Music, en el proyecto para el Puente de la Academia, en Double Rhythm y en Double Arch.

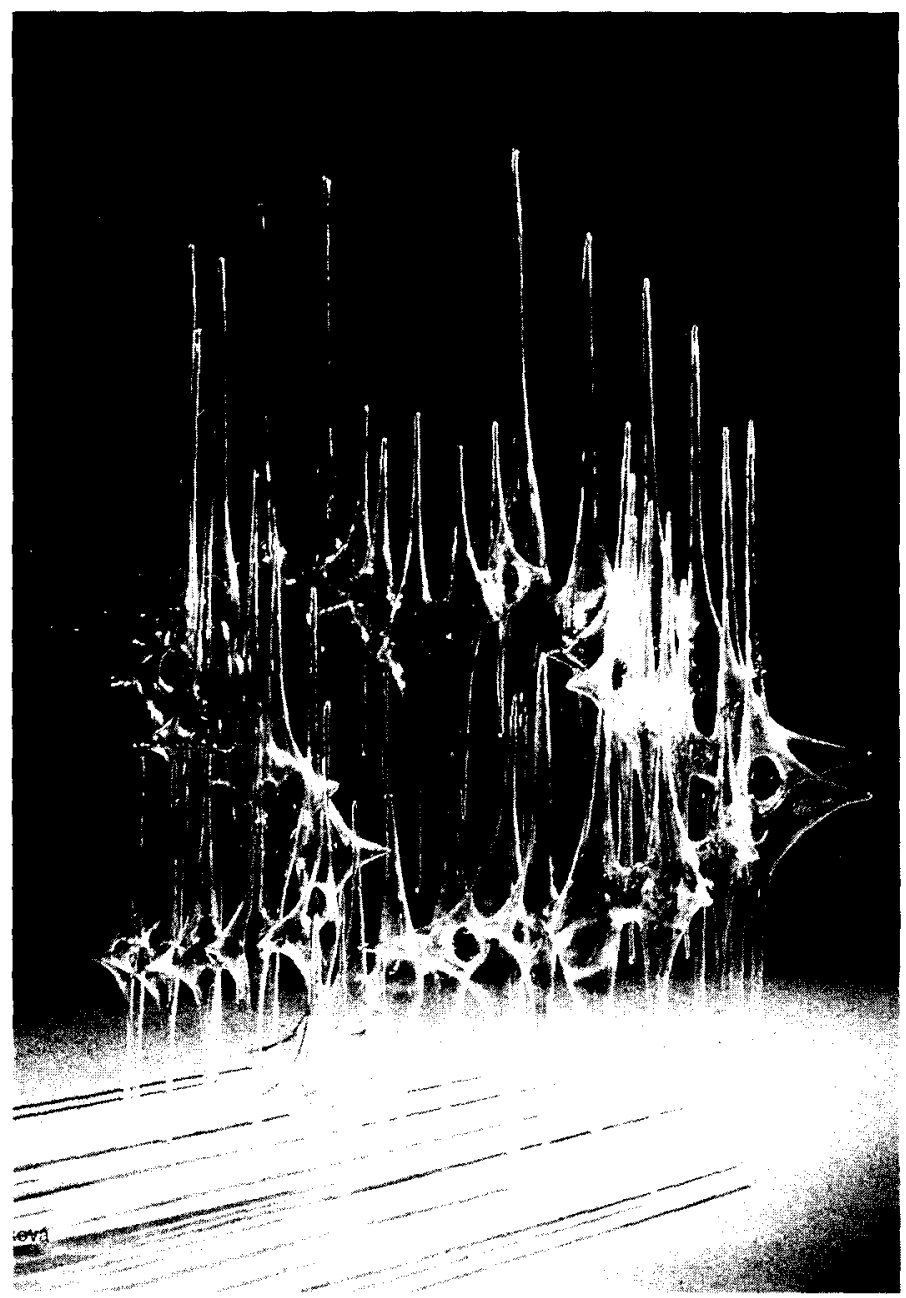

Fig. 1. Vera Lisková: Music, $100 \times 90 \times 85 \mathrm{~cm} ., 1977$ 


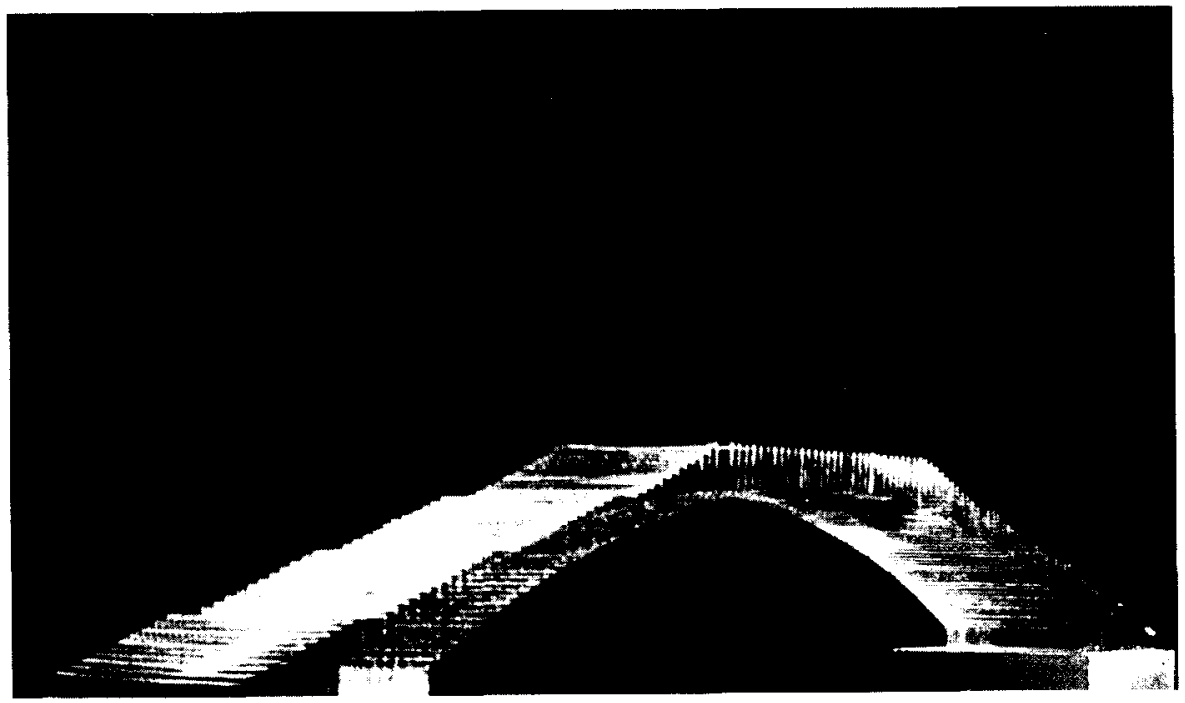

Fig. 2. Luciano Vistosi: Proyecto para el Puente de la Academia (Venecia), $400 \mathrm{~cm}$. de luz, 1984-1985.

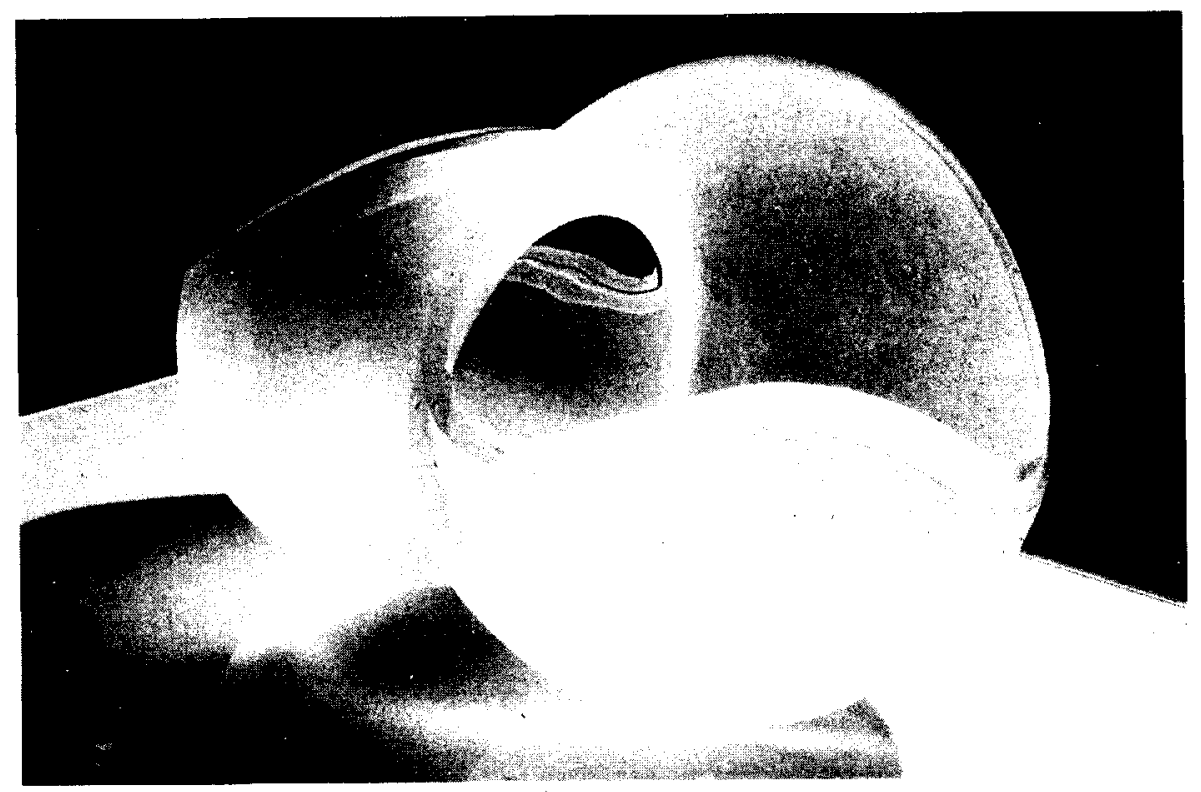

Fig. 3. Stephen Procter: Double Rhythm, $295 \times 89 \times 455 \mathrm{~cm}$., 1985. 


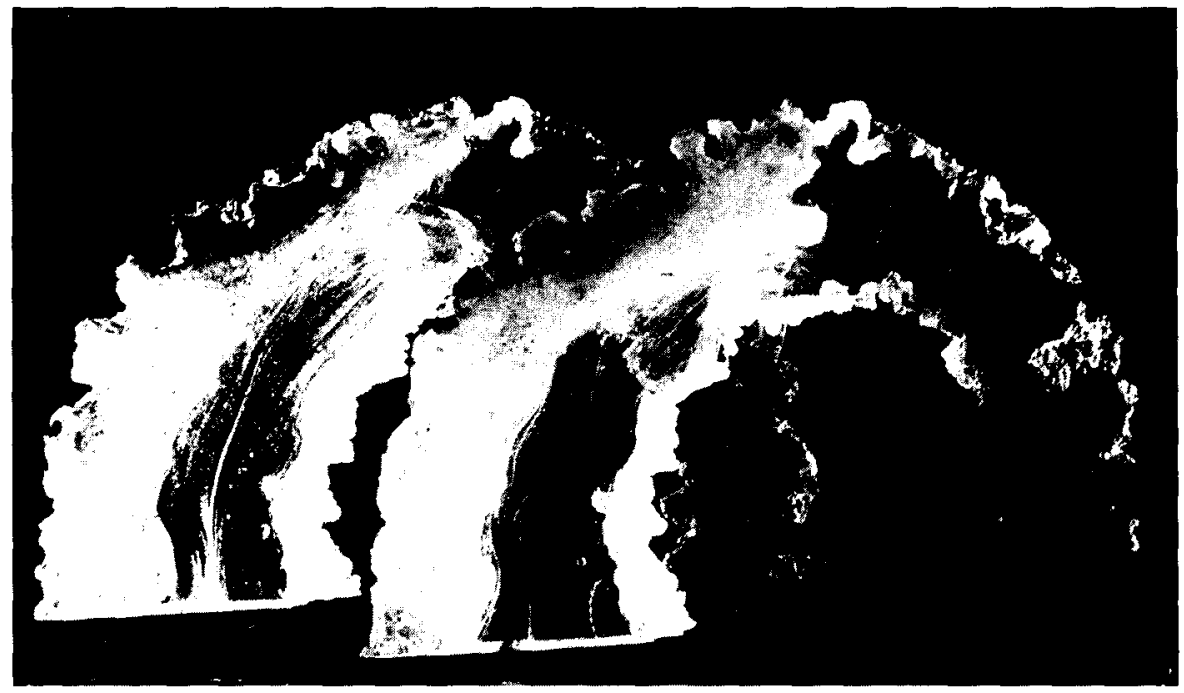

Fig. 4. Colin Reid: Double arch, $27 \times 47 \times 65 \mathrm{~cm} ., 1985$.

Aunque España se ha incorporado con un cierto retraso a esta nueva vertiente del lenguaje escultórico, no son pocos los escultores que han descubierto en el vidrio su medio de expresión plástica. Uno de ellos es Pedro García (Arandilla, Burgos, 1954), quien junto a Joaquín Torres Esteban ${ }^{3}$ y Javier Gómez ${ }^{4}$, entre otros nombres que podrian ser citados, ha contribuido con su obra a ampliar en España el horizonte de la escultura en vidrio laminado.

Este escultor descubrió esta materia en el taller familiar a una edad muy temprana, intuyendo al contemplarla las posibilidades plásticas que podía encerrar. Cuando en 1974 inició su actividad artística, las formas geométricas fueron las que en un principio atrajeron su atención, por lo que superponía láminas de vidrio que generaban volúmenes cúbicos, de

Sobre Torres Esteban me he ocupado en mi estudio "Un material clásico para una renovación escultórica", en Los Clasicismos en el Arte Español. Madrid, Departamento de Historia del Arte, U.N.E.D., 1994, págs. 166-168, y especialmente en el Catálogo de la Exposición Torres Esteban, una pasión por el vidrio. Centro Nacional del Vidrio, La Granja de San Ildefonso, Segovia, 8 mayo $1998-28$ febrero 1999. 169-170.

"Sobre Javier Gómez, véase: GonzAlez VICARIO, M.T.; “Un material clásico para ...", págs.

- "El vidrio y la forma construida en la escultura de Javier Gómez". Goya, Madrid, n. ${ }^{\circ} 258$, 1997, págs, 361-368.

- "La práctica artística del escultor contemporáneo y los materiales". Espacio, Tiempo y Forma, U.N.E.D., Madrid, 1997, Serie VII, Historia del Arte, T. 10, págs. 306 y 307. 
perfiles rotundos, enriquecidos por la presencia de espacios interiores, mientras que en otras obras se valoraba el dinamismo que el giro de las láminas ocasionaba.

A esta primera etapa corresponden obras como las tituladas Elevación I y Elevación II, realizadas en 1979 y 1984 respectivamente. Entre la ejecución de una y otra pieza han transcurrido unos años, el tiempo suficiente para advertir determinados cambios en el proceso evolutivo de Pedro García. Como es habitual en esta fase inicial, las esculturas son concebidas según unas soluciones plásticas de marcado carácter arquitectónico, que suponen la valoración de la materia en función de la clara y ordenada distribución de los elementos compositivos y de las relaciones espaciales que se establecen entre ellos.

Elevación I (fig.5) es una estructura en la que el vidrio laminado se combina con el espacio para originar lo que en definitiva es la maqueta de un rascacielos, con lo que se pone de manifiesto que para Pedro García el vidrio no sólo es un material escultórico sino también arquitectónico. En su opinión, está llamado a aumentar el protagonismo que ya tiene en la arquitectura, hasta el extremo de poderse utilizar como único material de construcción en un edificio. El planteamiento de esta pieza, resuelta en función de la verticalidad y horizontalidad de sus elementos estructurales, se repite en Elevación II. Sin embargo, las formas no son tan estáticas, ya que se ha introducido una variante con respecto a la anterior obra al perforar la materia para originar dos arcos, con lo que se subraya la presencia del espacio, a la vez que el mayor protagonismo de lo curvo suaviza los perfiles del volumen escultórico.

Su firme convicción en las posibilidades arquitectónicas del vidrio laminado le llevaron en estos años a la realización de la obra titulada $A$ un monumento, creada como homenaje a todos los que jalonan la historia de la Arquitectura. La materia y el espacio se han combinado en esta escultura para originar distintas soluciones formales que suponen un señalado contraste. Es, en definitiva, el encuentro de dos volúmenes geométricos - pirámide y esfera- que siendo diferentes, se complementan; pero en esta obra también se percibe el diálogo que se establece entre la materia y el vacio, las formas estáticas y las dinámicas, los espacios interiores y el que rodea a la escultura, en la que, además, la tonalidad verdosa del material se ve alterada por el contraste que ofrecen determinados elementos compositivos realizados en vidrio cobrizo ("creolé»).

La escultura de Pedro García reclama la presencia del color, no sólo del que se deriva de la mayor o menor opacidad del vidrio, capaz de 


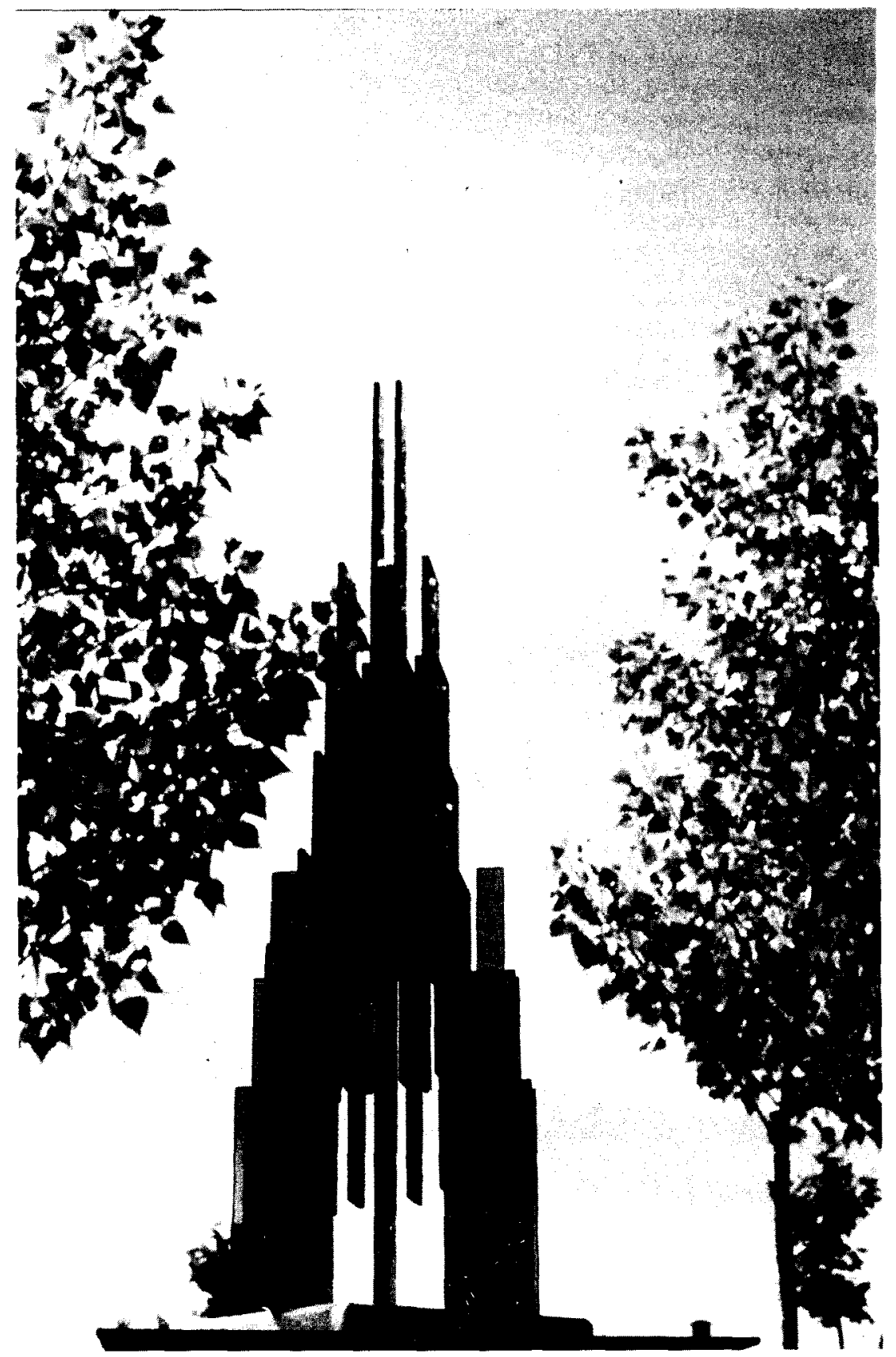

Fig. 5. Elevación I, $80 \times 30 \times 30 \mathrm{~cm}, 1979$. 
generar matices diferenciadores en su natural tonalidad verde, sino también del que se obtiene con otros contrastes cromáticos. En Núcleo de fuego (fig. 6) unas láminas circulares de vidrio rosa se han ido superponiendo hasta configurar el núcleo de un volumen cilíndrico, compacto y sólido. Su color rojizo nos sugiere la presencia del fuego que pugna por romper la materia que lo aprisiona, un vidrio incoloro que se torna verde en la medida que lucha con el fuego que imaginamos, pero que al alejarse de él pierde fuerza, y al debilitarse, se vuelve transparente.

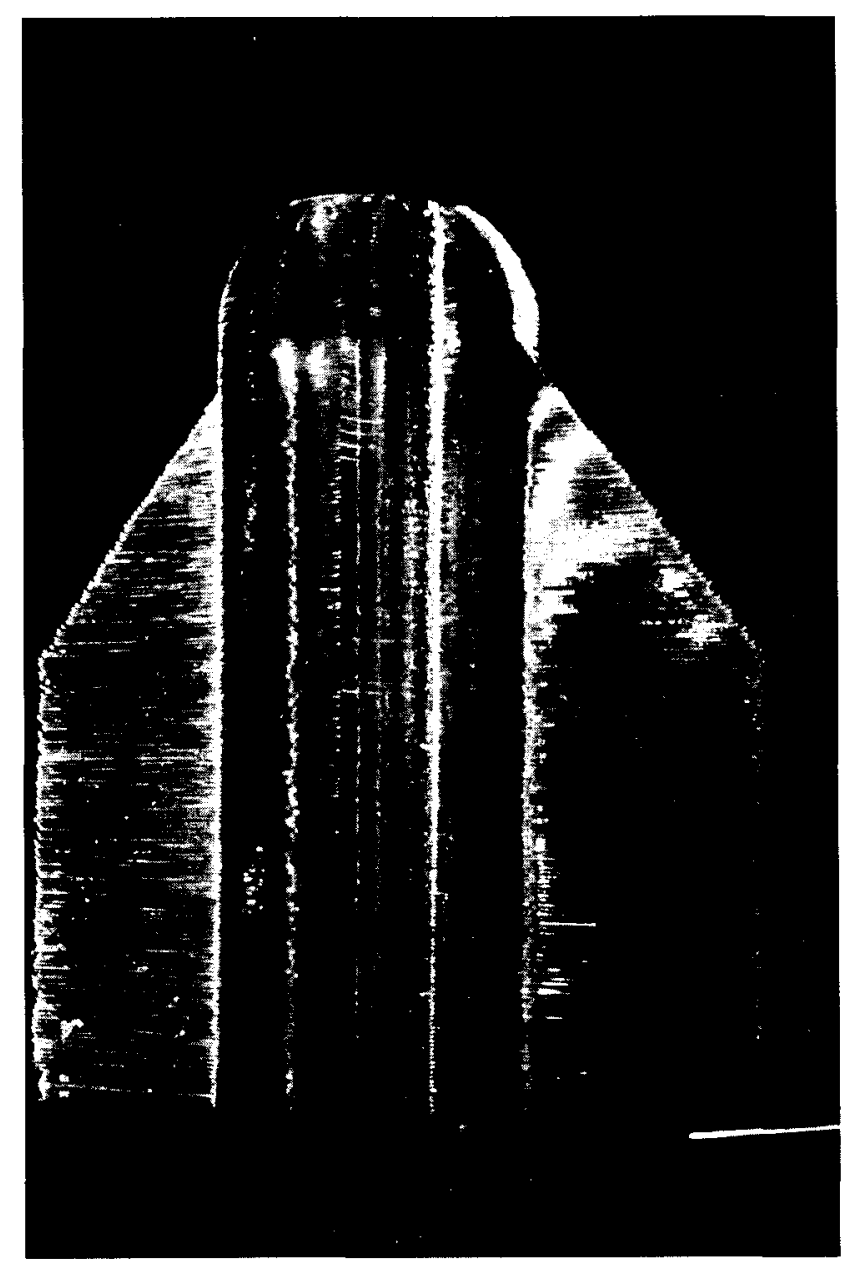

Fig. 6. Núcleo de fuego, $64 \times 67 \times 30 \mathrm{~cm}$, 1981 . 
A este mismo planteamiento constructivo, racionalista, responde la obra titulada Esculpiendo un torso (fig. 7), aunque en ella las láminas de vidrio ya no se ordenan en el espacio para originar unos volúmenes escultóricos que nos sugieren arquitecturas a escala reducida, sino, por el contrario, el objetivo del escultor en esta pieza ha sido profundizar en las posibilidades plásticas de una materia capaz de abandonar la rigidez

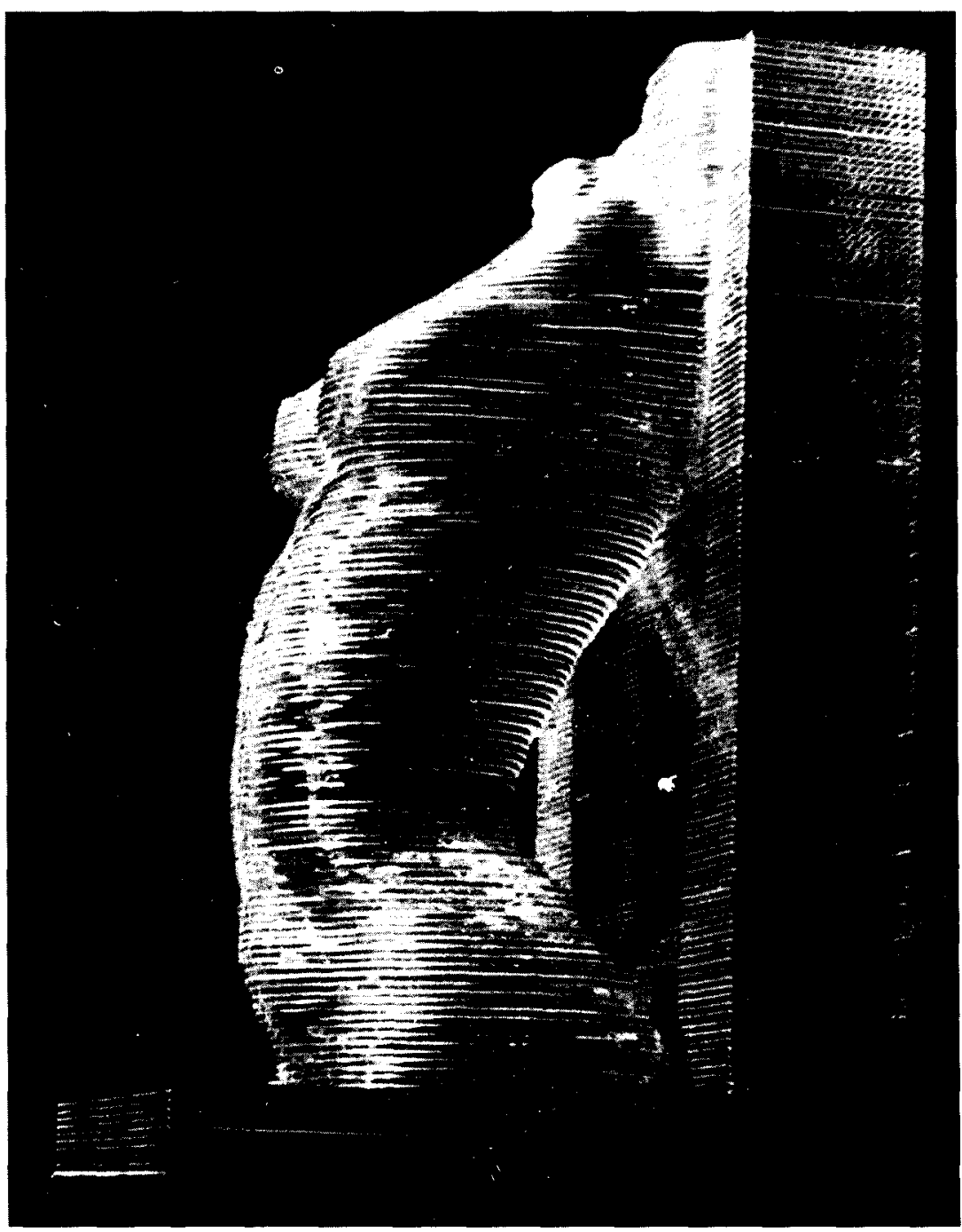

Fig. 7: Esculpiendo un torso, $40 \times 26 \times 25 \mathrm{~cm} ., 1983$. 
de su estructura geométrica para transformarse, como si fuese mármol, en un torso femenino. Resulta evidente que el procedimiento técnico que se ha seguido en su ejecución es diferente al que este último material hubiera requerido, puesto que Pedro García no ha tallado un bloque de vidrio, sino que después de cortar las láminas en función del volumen escultórico que quería conseguir, las ha ido superponiendo y organizando en el espacio hasta conseguir los efectos deseados. Por un lado, ha subrayado las posibilidades escultóricas del vidrio con el que ha construido este torso femenino, al establecer una relación entre sus ritmos curvos y ondulantes y la verticalidad y horizontalidad de la estructura geométrica que lo acoge, cuyos planos y líneas intensifican los valores expresivos del torso. Por otro lado, la incidencia de la luz sobre la materia al rozar sus superficies y penetrarlas acentúa la plasticidad de esta obra.

Algo posteriores, pero también dentro de esta etapa de la evolución artística de Pedro Garcia, son Mirando hacia atrás, Paisaje submarino y Caminando libremente. En todas ellas se ha seguido trabajando el vidrio en frío, técnica que individualiza a este periodo de los restantes, y que supone, como ha podido apreciarse, la disposición vertical y horizontal de las láminas de vidrio hasta configurar formas escultóricas. En Caminando libremente (fig. 8), la superposición de los elementos compositivos genera una sucesión de perfiles que dependiendo del espesor de la materia, aumenta o disminuye su cromatismo o transparencia y, consecuentemente, también su volumen, a la vez que los ritmos curvos sugieren la sensación de movimiento.

A esta fase siguió otra en la que Pedro García utiliza vidrio termoformado. La transición entre ambas etapas viene señalada por la obra Dar, recibir, ir y venir (fig. 9) en la que el escultor continúa empleando el vidrio laminado en frío para el soporte, a la vez que introduce el vidrio termoformado, una técnica que se convertiría en su centro de interes, sin que ello deba interpretarse como un abandono de la empleada en la etapa anterior.

Para Pedro García ésta es una pieza clave en su proceso evolutivo, pero, al mismo tiempo, también representa su "reencuentro" con la escultura tras sufrir un grave accidente en una mano. La incertidumbre del ser humano ante el futuro, su miedo frente a lo inesperado, ante aquello que repentinamente puede truncar su existencia, es lo que simboliza la mano fragmentada, partida cruelmente en dos por un "boomerang". Ambos elementos formales han sido realizados en vidrio termoformado, técnica que también supone la utilización del vidrio laminado, pero no 


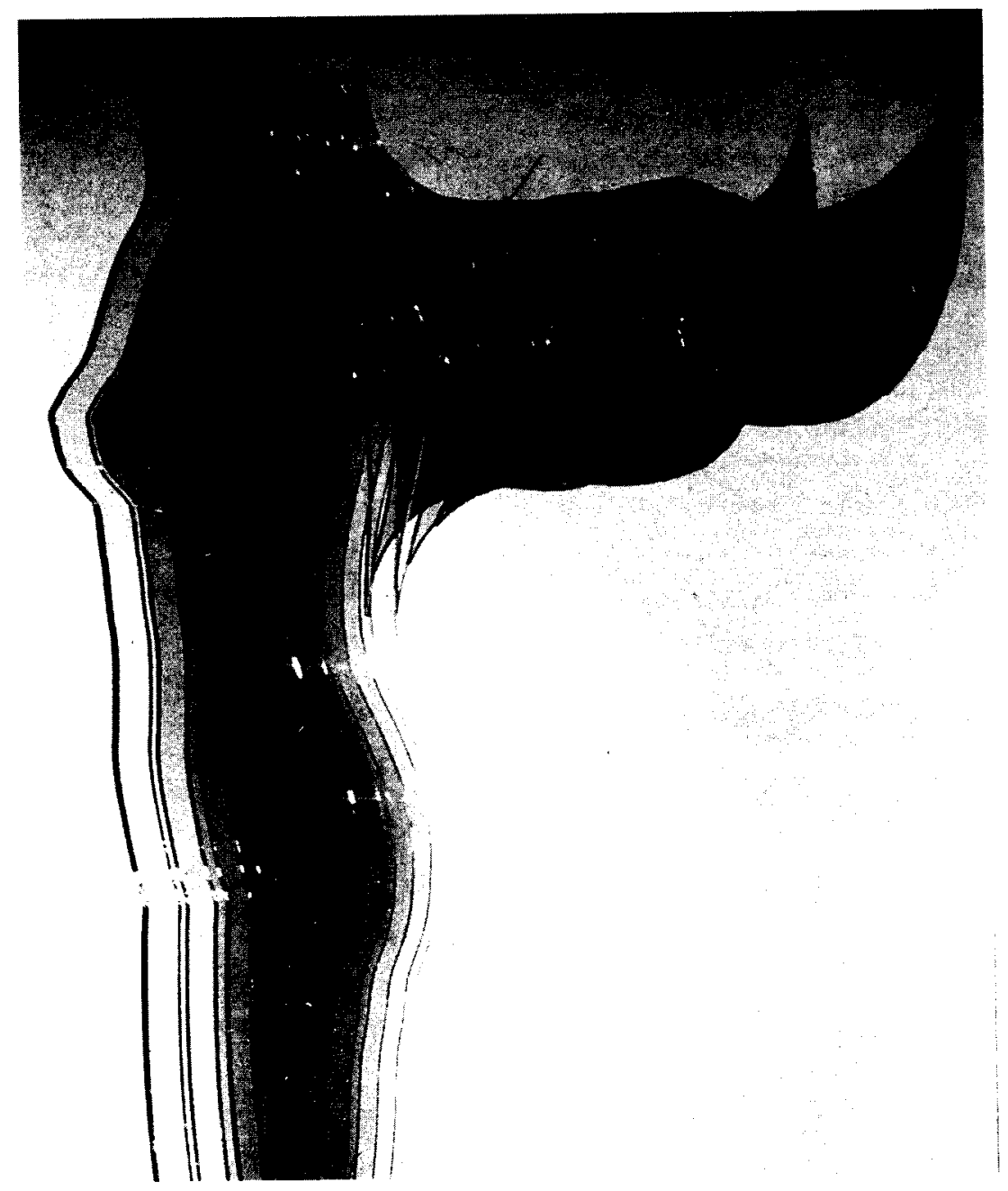

Fig. 8: Caminando libremente, $150 \times 100 \times 40 \mathrm{~cm} ., 1986$. 


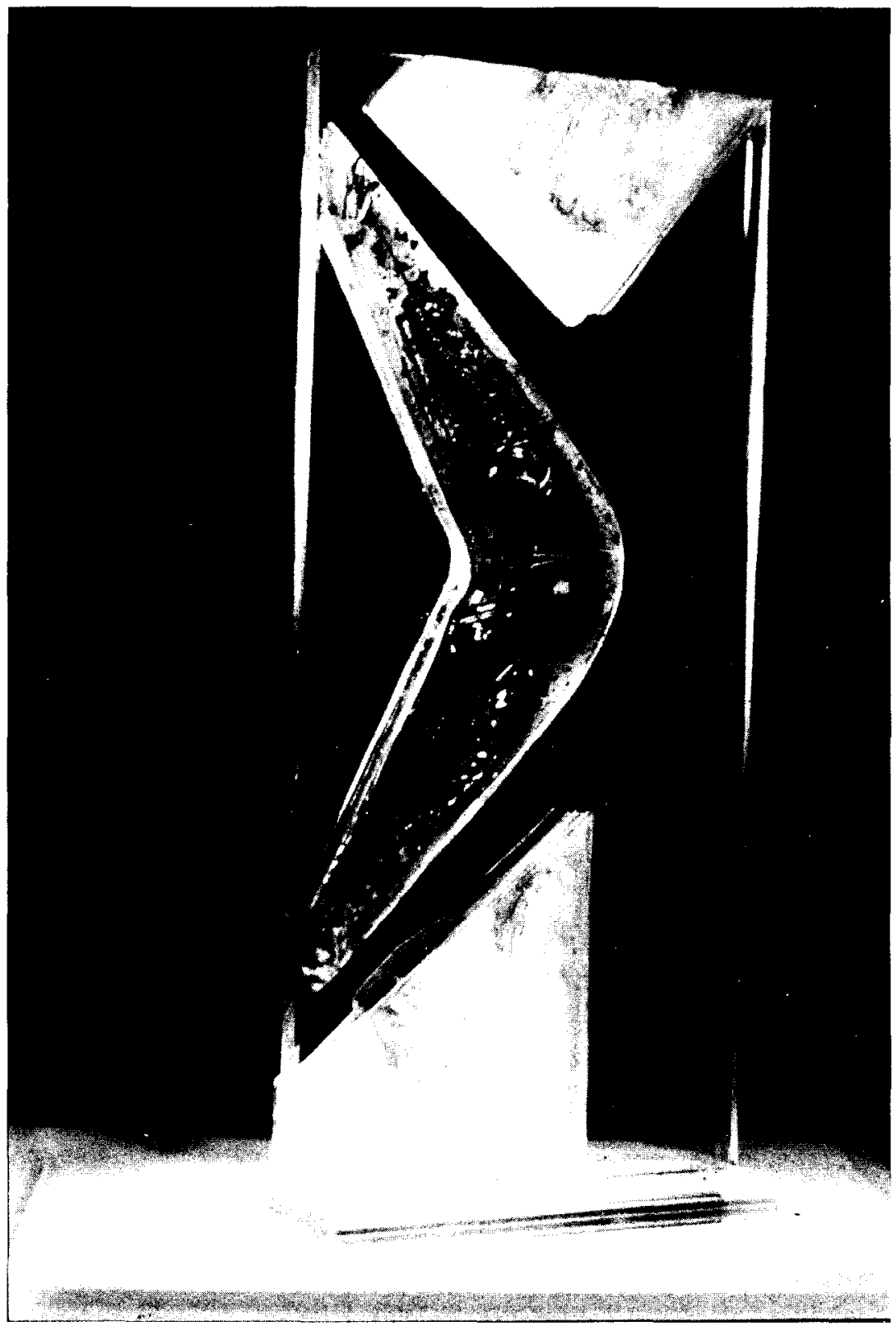

Fig. 9. Dar, recibir, ir y venir, $77,5 \times 34,5 \times 13 \mathrm{~cm}$., 1988 . 
tratado en frío, es decir, no unido con pegamento, sino sometido a la acción del fuego, que lo transforma en una materia dúctil y maleable. De esta manera, las formas obtenidas por este procedimiento se oponen en esta pieza a la verticalidad y horizontalidad del vidrio tratado en frío, y también a su transparencia y rigidez. Además, el interés de Pedro Garcia por el arte de los indígenas australianos le ha llevado a emplear en el "boomerang" su misma gama de colores: el amarillo, el negro y el rojo, pero enfatizando la presencia del rojo por su fuerza expresiva.

Aunque esta segunda etapa, iniciada en torno a 1986, está integrada por obras que en su mayoría han sido realizadas en vidrio termoformado, existen, sin embargo, determinadas piezas en las que se sigue empleando el vidrio trabajado en frio, como sucede en Perfil y en Monolitos de carne $y$ hueso. En la primera de ellas, Perfil, esta materia ha adoptado una apariencia nueva al estar dominada por el protagonismo de lo curvo y por lo acusado de sus ritmos envolventes. Las láminas de vidrio, dispuestas en sentido vertical, han ido configurando el perfil de una mujer de marcada personalidad, muy segura del papel que debe desempeñar en la vida. El escultor exalta estas cualidades a través de un volumen escultórico que presenta una clara diferenciación cromática y unos perfiles dinámicos y agresivos, subrayados por la incidencia de la luz sobre la materia.

Monolitos de carne y hueso es una instalación integrada por cuatro piezas: Monolitos de carne y hueso, que adopta el título genérico de dicha instalación, Tierra y aire, Transparencias y Eternos ${ }^{5}$. Estas obras, dispuestas en zigzag para obligar al espectador a desplazarse a su alrededor, ocupaban el centro de la sala de exposiciones sobre unas bases realizadas con guijarros, arena y vidrio triturado, fraguados con resina, y que aludian al origen del vidrio. En cada una de ellas se abría una ranura que albergaba a un personaje de vidrio laminado, trabajado en frío, tratado con chorro de arena y posteriormente coloreado. Mientras la primera de las piezas, Monolitos de carne y hueso, representaba al conjunto de la instalación bajo la apariencia de una figura masculina, en Tierra y aire, un adolescente aludía a los componentes que integran el vidrio y al lejano e incierto momento en que fue descubierto por el hombre; en Transparencias, Pedro García prefirió representar una figura femenina para evocar la transparencia de esta materia, ya que según su opinión existe una gran similitud entre la mujer y el vidrio; y, finalmente, Eternos (fig. 10), un personaje que por su tamaño dominaba el conjunto, símbolizando lo que para Pedro

Esta instalación formó parte de la exposición que con el titulo Formas vivas tuvo lugar en la Galeria Velázquez cie Valladolid, en marzo de 1991. 

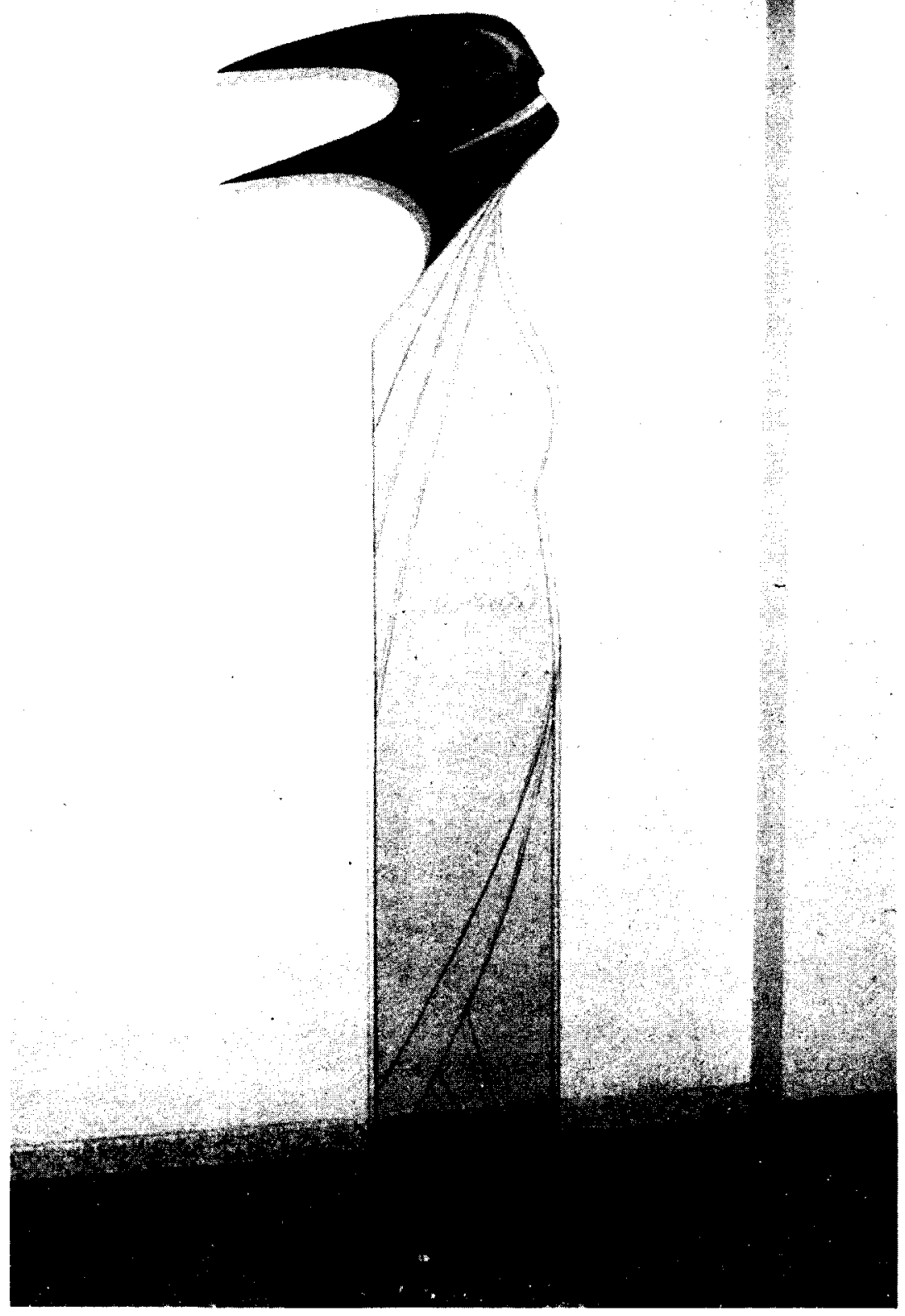

Fig. 10. Eternos, $240 \times 60 \times 60 \mathrm{~cm} ., 1991$. 
García constituye una obsesión: el Vidrio con mayúscula, una materia que está llamada a ocupar un lugar muy destacado en el Arte. Esta instalación aludia, por lo tanto, a la evolución del vidrio, desde su formación y posterior descubrimiento por el hombre hasta alcanzar en la actualidad el lugar que le corresponde en el arte contemporáneo.

Sin abandonar, por lo tanto, la técnica empleada en la primera etapa de su evolución artística, Pedro García se decanta en la segunda fase por el vidrio termoformado, como ya se indicó con anterioridad. La serie titulada Inclusiones marca un período en que el escultor, buscando arrancar a la materia nuevos valores expresivos, se inclina por un procedimiento que le entrenta al fuego. Es entonces cuando a su mente acuden recuerdos de la niñez, de aquellos días fríos en los que una chimenea era el eje de sus juegos, que le llevaban a arrojar fragmentos de vidrio al fuego para ver cómo éste los transformaba, mientras la ceniza los manchaba con impurezas. En aquel pueblo, en aquella chimenea y en aquellas brasas se esconde para Pedro García el origen de sus inquietudes artísticas, unas inquietudes que en esta etapa le han llevado a una transformación del vidrio al incluir entre las láminas materias que le son extrañas. De ahí el título de Inclusiones para la serie que llena esta segunda fase.

Por otra parte, la naturaleza es una constante fuente de inspiración para Pedro García. Este escultor se siente atraído por los valores plásticos que encierra un olivo, una raíz, una roca o una simple caracola, y valora tambiér la belleza de la fuerza del mar rompiendo contra las rocas. Mar en Pindal (fig. 11) es una obra inspirada en las formas escarpadas y abruptas de un acantilado, pero también en aquellas pinturas prehistóricas que decoran las cuevas de Pindal o Altamira. Como en ellas, unas manchas de color rojo y negro han ido configurando formas a las que la convexidad de la materia ha prestado su corporeidad. Son formas que se superponen, y con las que Pedro Garcia ha querido evocar aquellas pinturas prehistóricas realizadas sobre protuberancias naturales para lograr la sensación de vida y naturalismo.

Esos mismos colores han sido empleados en la obra titulada Bisonte de Altamira (fig. 12), en la que una vez más el escultor muestra su interés por las manifestaciones artísticas del Magdaleniense. Al igual que hicieron los hombres primitivos, él también ha utilizado materias orgánicas para conseguir determinados pigmentos que se suman a otros colorantes químicos. Las formas que las manchas de color generan, aprisionadas entre las láminas de vidrio, parecen ocupar en esta pieza un espacio nebuloso, sugerido por la incidencia de la luz sobre la materia y por la oscuridad de su entorno. 


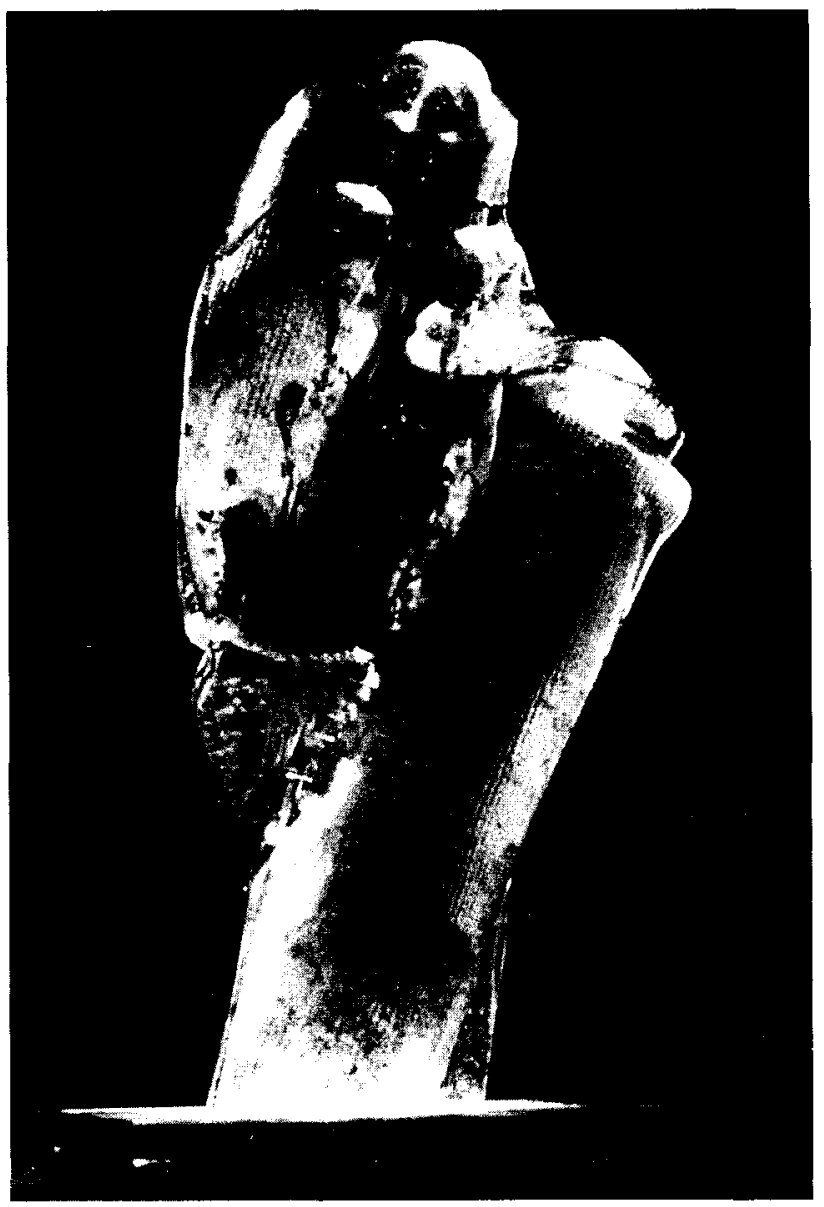

Fig. 11. Mar en Pindal, $73 \times 40 \times 26,1994$

Las obras que integran esta segunda etapa se caracterizan por la transformación del vidrio laminado, que cobra una nueva identidad al asumir la forma de un molde tras ser sometido a la acción del fuego. Sus superficies se curvan, renunciando a la bidimensionalidad, al frío rigor de su geometría y a la verticalidad y horizontalidad que generan sus planos. Son obras cuya estructura responde a soluciones organicistas al estar inspiradas en las formas de la naturaleza y del cuerpo humano. Pero también se busca en ellas la expresividad de la materia, los efectos de textura que incitan a acariciar sus superficies irregulares, unas veces suaves, pulimentadas, y otras, ásperas y rugosas, que ocultan una vida 


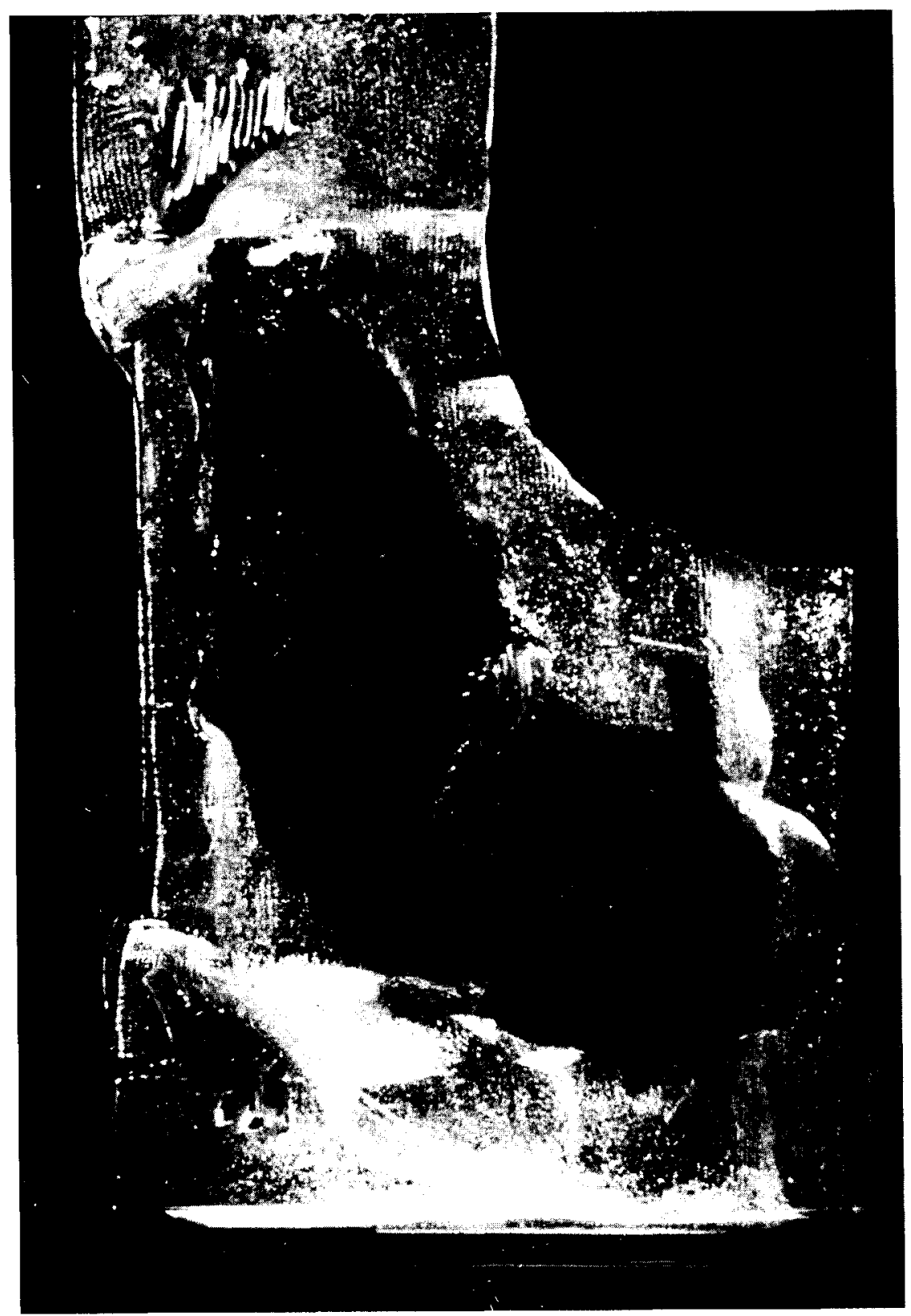

Fig. 12. Bisonte de Altamira, $89 \times 64 \times 25 \mathrm{~cm}, 1994$. 
interior. La obra, por lo tanto, se revela como algo que reclama el tacto del espectador, al atraerle no sólo por su apariencia formal, sino también por sus calidades matéricas y por lo enigmático del mundo que encierra, ya que, como señala René Berger, "la materia no es sencillamente aquello por lo que la forma se hace visible, sino aquello por lo que la forma se hace sensible" ${ }^{6}$. Ese misterio, ese enigma que encierra el vidrio, es debido al interés de Pedro García por explorar los efectos ópticos del color, que le lleva a aprisionar diferentes sustancias entre las láminas de vidrio: polvos cerámicos, oxidos metálicos, colorantes químicos, papel de oro o plata, minerales, cáscara de huevo, espinas de pescado, fragmentos de agujas de cedro, ramas de enebro, hojas..., algo que, por otra parte, ya fue valorado por Josef Albers cuando resaltó los innumerables tintes y matices que se pueden descubrir en las hojas, al referirse al brillante colorido que presenta el follaje otoñal ${ }^{\text {? }}$. Pero, al mismo tiempo, esta inclusión de sustancias orgánicas en la obra de Pedro García puede ser también un testimonio del peligro de desaparición que amenaza a la naturaleza.

En Caminante a Santiago (fig. 13) el vidrio laminado encierra en su interior, junto a otras materias orgánicas, unas amarillentas ramas de enebro y dos ennegrecidos caballitos de mar. Además, las tonalidades verdes y azules evocan el paisaje que los ojos del peregrino contemplarán en su recorrido, mientras que la acusada verticalidad originada por la disposición de las láminas de vidrio sugieren el cuerpo del caminante. Aunque se trata de una obra abstracta, sin embargo, la presencia de esos ritmos verticales, interrumpidos por otros horizontales que la consciente fragmentación de la materia ha provocado, aluden al bastón en el que se apoya el peregrino y a sus vestiduras movidas por el viento.

En la obra de Pedro García se combina frecuentemente el vidrio con el hierro, pero mientras en algunas piezas, como en Caminante a Santiago, este último material sólo sirve de soporte, en otras comparte el protagonismo con el vidrio. Silla (fig. 14) es una escultura en la que unas varillas de hierro forjado ascienden desde su base, también de hierro, para dibujar en el espacio el perfil de una silla isabelina, aunque sería más exacto decir la versión, muy personal, que de la misma nos da el escultor. El vidrio, por su parte, representa la cabeza de un personaje que se supone está sentado sobre ella. Pero, quizá, lo más significativo de esta obra es el juego pág. 72.

6 Berger, R.: El conocimiento de la pintura. El arte de verla. Barcelona-Madrid, Noguer, 1976,

Albers, J.: La interacción del color. Madrid, Alianza Editorial, 1979, págs. 68 y 69. 


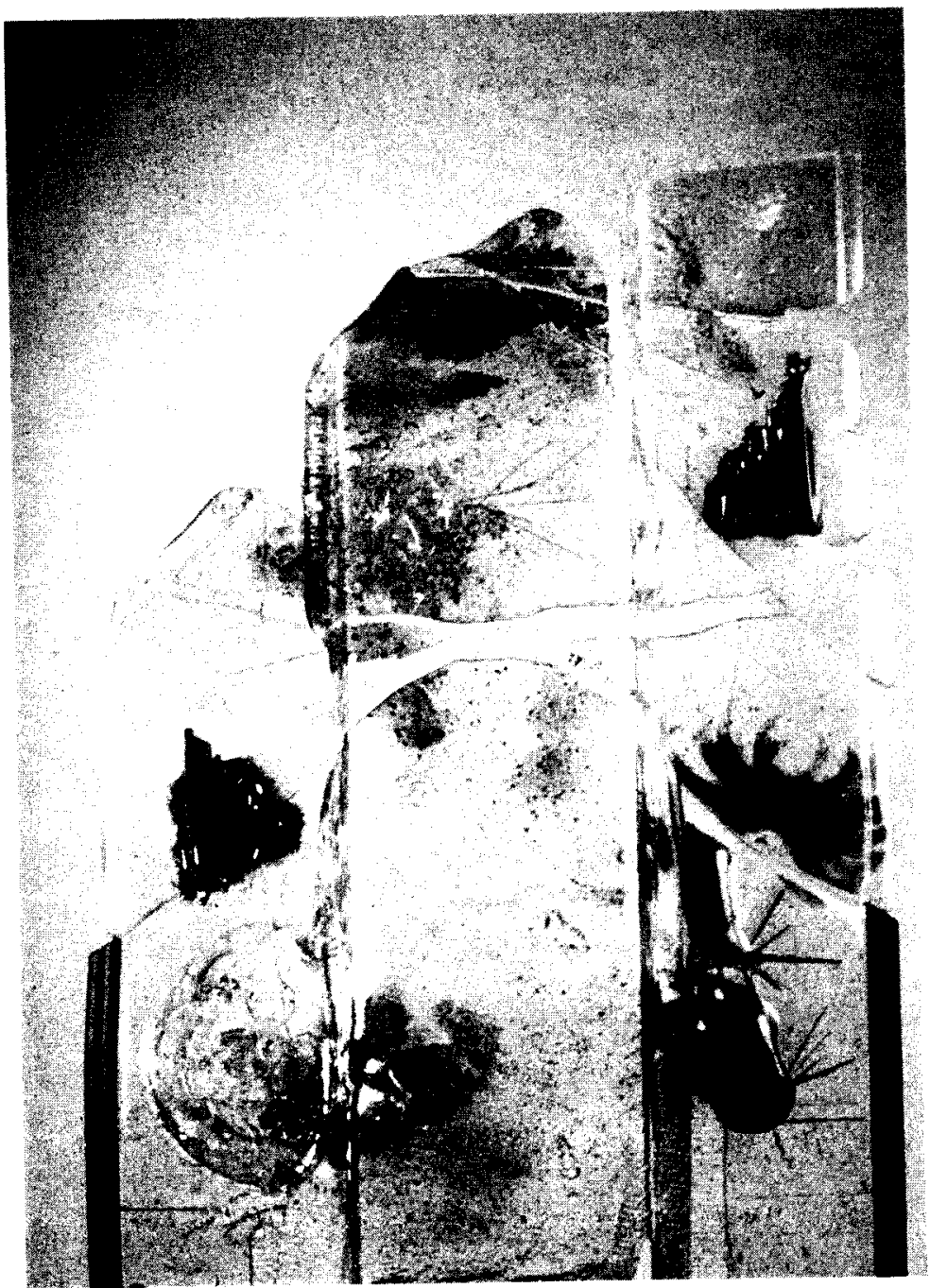

Fig. 13. Caminante a Santiago, $91 \times 69 \times 20 \mathrm{~cm} ., 1994$. 


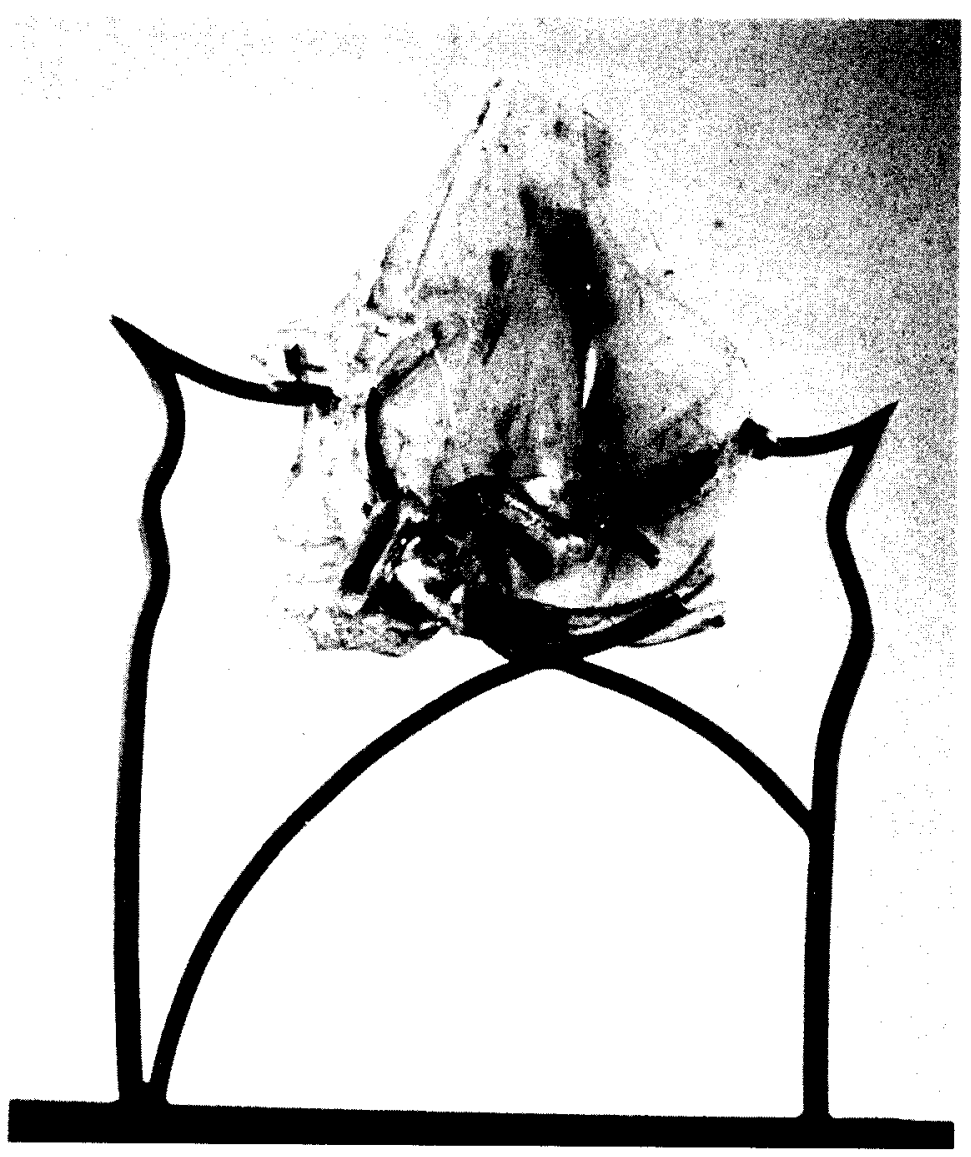

Fig. 14. Silla, $58 \times 71 \times 14 \mathrm{~cm}, 1994$.

que se establece entre ambos materiales y el espacio. Por un lado, el hierro, que parece crecer en el vacio, generando en su recorrido expresivos perfiles; por otra parte, el vidrio, que ha sido deformado hasta adquirir la tridimensionalidad, y que aprisiona los fragmentos de una silla y sus tornillos. Además de la combinación de estos materiales, la valoración que se hace en esta obra del espacio y de los efectos lumínicos intensifican su eficacia expresiva.

Este protagonismo compartido entre el vidrio y el hierro vuelve a repetirse en Mástil (fig. 15), una obra concebida por Pedro García para ocupar un espacio público y, desde allí, reclamar con su presencia la atención del espectador, atrayéndole con la intensidad del color azul del vidrio que 


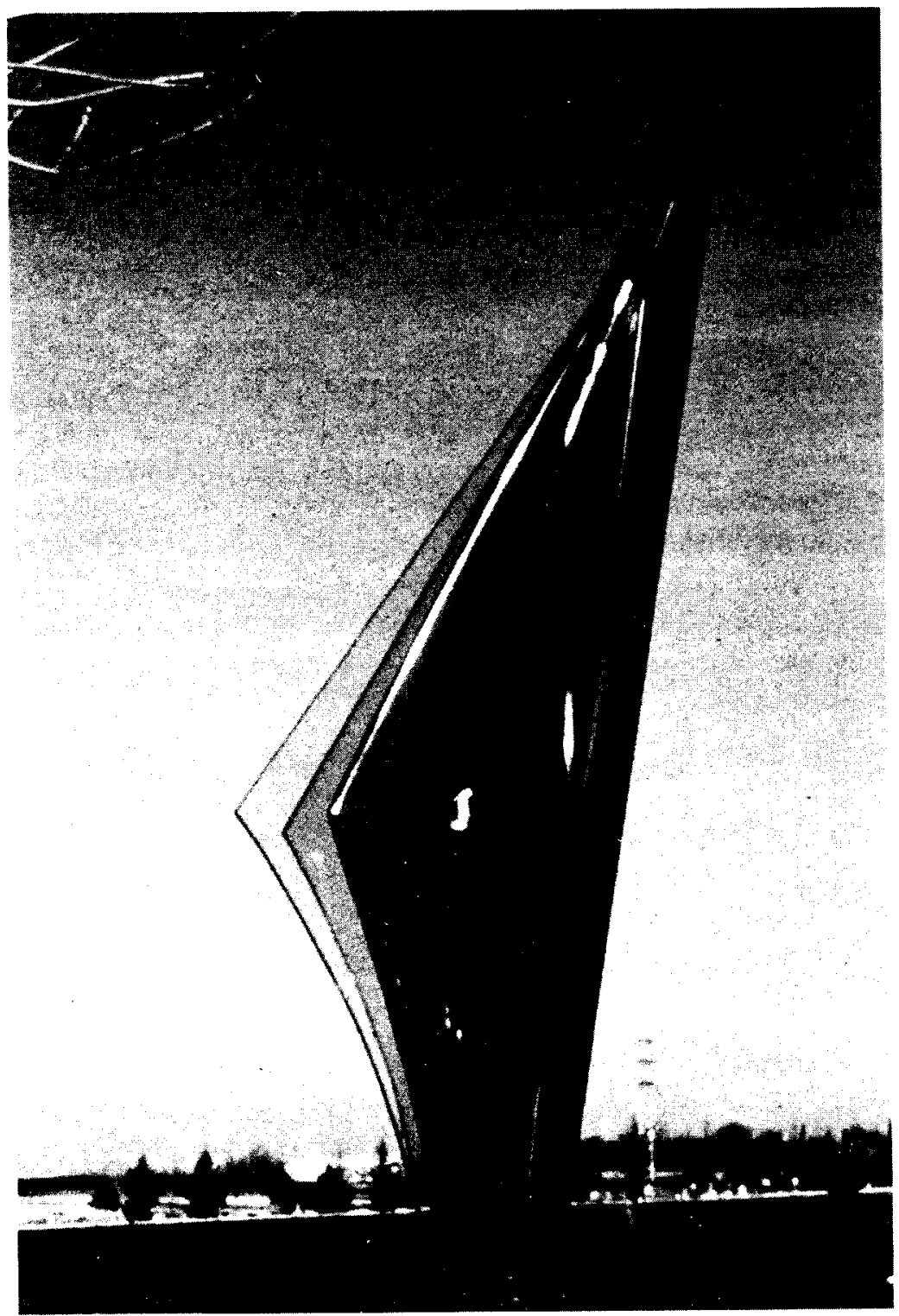

Fig. 15. Mástil, $154 \times 50 \times 63 \mathrm{~cm} ., 1995$. 
inevitablemente hace recordar el de las aguas del mar, cuando son acariciadas por el resplandor del sol. Pero a su lado, el hierro, transformado en uno de los palos de un velero, ofrece un señalado contraste por su negrura y opacidad que hace resaltar la belleza del vidrio laminado, su tonalidad y condiciones reflectantes, que pueden ser alteradas por un cambio de ambiente. Esta última materia, sometida a una determinada temperatura, ha modificado su estructura al adaptarse a siete moldes distintos que han curvado la superficie de cada lámina para adoptar las posiciones diferentes de una vela impulsada por el viento. Una vez más el hierro y el vidrio se complementan en la obra de Pedro García, necesitando cada uno de estos materiales la presencia del otro, de igual forma que la vela de una embarcación no tiene sentido sin su mástil.

En Columna vertebral, realizada en 1995, el hierro es la prolongación de los fragmentos de una silla aprisionados por el vidrio, de tal manera que ambos materiales - la madera y el hierro- forman una unidad que en parte configuran la superposición de las treinta y tres vértebras que integran la columna vertebral del ser humano. Sin embargo, en la serie Inclusiones existen piezas en las que se ha buscado relacionar el vidrio con una sola materia. Inclusión de raiz, Inclusión de sarmiento o Inclusión calcárea, todas ellas de 1995, son obras en las que el vidrio encierra en su interior una raíz, un sarmiento o una concha, respectivamente, cuya huella es apreciable en el exterior de cada pieza como testimonio del material que cada una de ellas contiene.

A esta segunda fase siguió otra, iniciada en 1995 -la última, por el momento- en la que sin abandonar las investigaciones anteriores, se aprecia un nuevo planteamiento formal en la evolución artística de Pedro García. En las obras que integran la serie denominada Percepciones fragmentadas, el escultor centra su interés, como indica el título de dicha serie, en la representación de un fragmento del cuerpo humano tal y como él lo ha percibido, deteniéndose en la valoración de los detalles, recreándose en ellos, pero, al mismo tiempo, buscando también la plasticidad que se deriva de la metamorfosis operada en el vidrio. En la realización de estas obras se ha seguido el mismo procedimiento que en las anteriores, es decir, se ha partido de un molde sobre el que se dispusieron láminas de vidrio con materiales químicos y orgánicos intercalados. Posteriormente, el fuego transformó el vidrio hasta convertirlo en una masa que se fue deslizando sobre el molde al igual que la lava de un volcán. El vidrio laminado asi tratado termina por fundirse con los materiales que lo acompañan hasta constituir una unidad, pero en su integración se ha desencadenado una lucha que Pedro Garcia describe con estas palabras: "Hago que el Vidrio luche contra la madera y produzca una tempestad, erosiones 
volcánicas dentro de la masa del Vidrio. Lo someto a altas temperaturas para que se rebele contra ese trozo de madera. Eso me produce la misma sensación que el mar " ${ }^{8}$. De esta manera, el frente posterior de cada pieza presenta unas superficies irregulares, de gran plasticidad, que recuerdan aquellas tierras afectadas por una gran actividad volcánica, y reclaman la atención de un espectador que necesariamente tendrá que desplazarse en torno a la obra para poder apreciarla en su totalidad.

Paseando entre algas, Pecho en escorzo, y Descubrimiento imprevisto son los títulos de algunas de las obras que integran la serie de Percepciones fragmentadas, en las que se evidencia la preocupación por captar la imagen de un pie al que acarician unas algas y las aguas del mar o el volumen de un pecho femenino. En Descubrimiento imprevisto (fig.16), Pedro García se enfrenta al vidrio una vez más, pero imaginándolo en esta ocasión como un bloque de piedra que un escultor ha de tallar para ir configurando un torso. Al golpear éste la materia con energía para definir

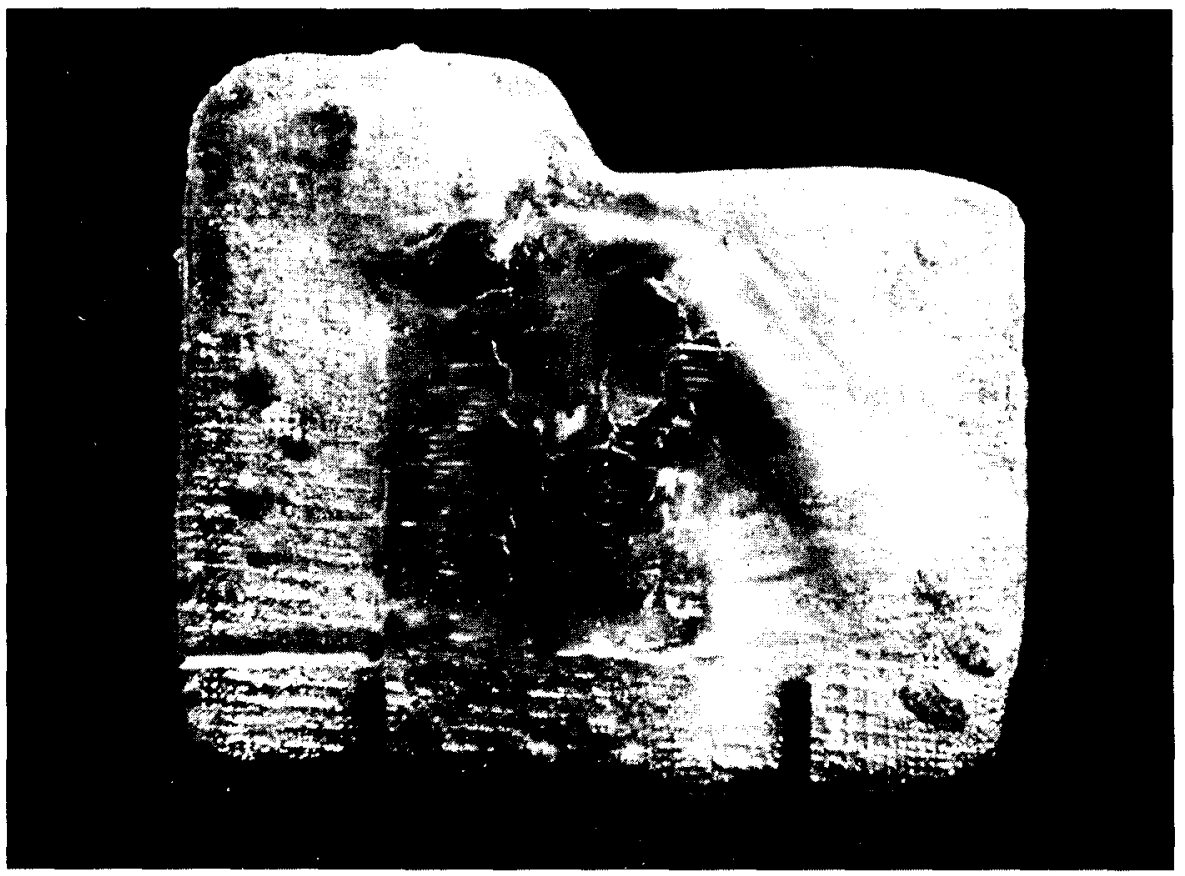

Fig. 16. Descubrimiento imprevisto, $53 \times 60 \times 18 \mathrm{~cm} ., 1995$.

8 Catálogo de la exposición Pedro Garcia. Percepciones fragmentadas (Texto: Ana María de Matos). Centro Municipal de las Artes, Alcorcón (Madrid), enero 1997, pág. 11. 
su forma, descubre inesperadamente que aquel bloque de piedra contiene unos fósiles, y los deja tal como los halla, intactos, sin atreverse a alterar lo que la naturaleza conservó durante siglos, aunque ello le obligue a dejar la escultura inacabada.

Inspirado en esta idea, Pedro García trabajó el vidrio laminado según su técnica habitual para darle la apariencia de un bloque, cuya tonalidad

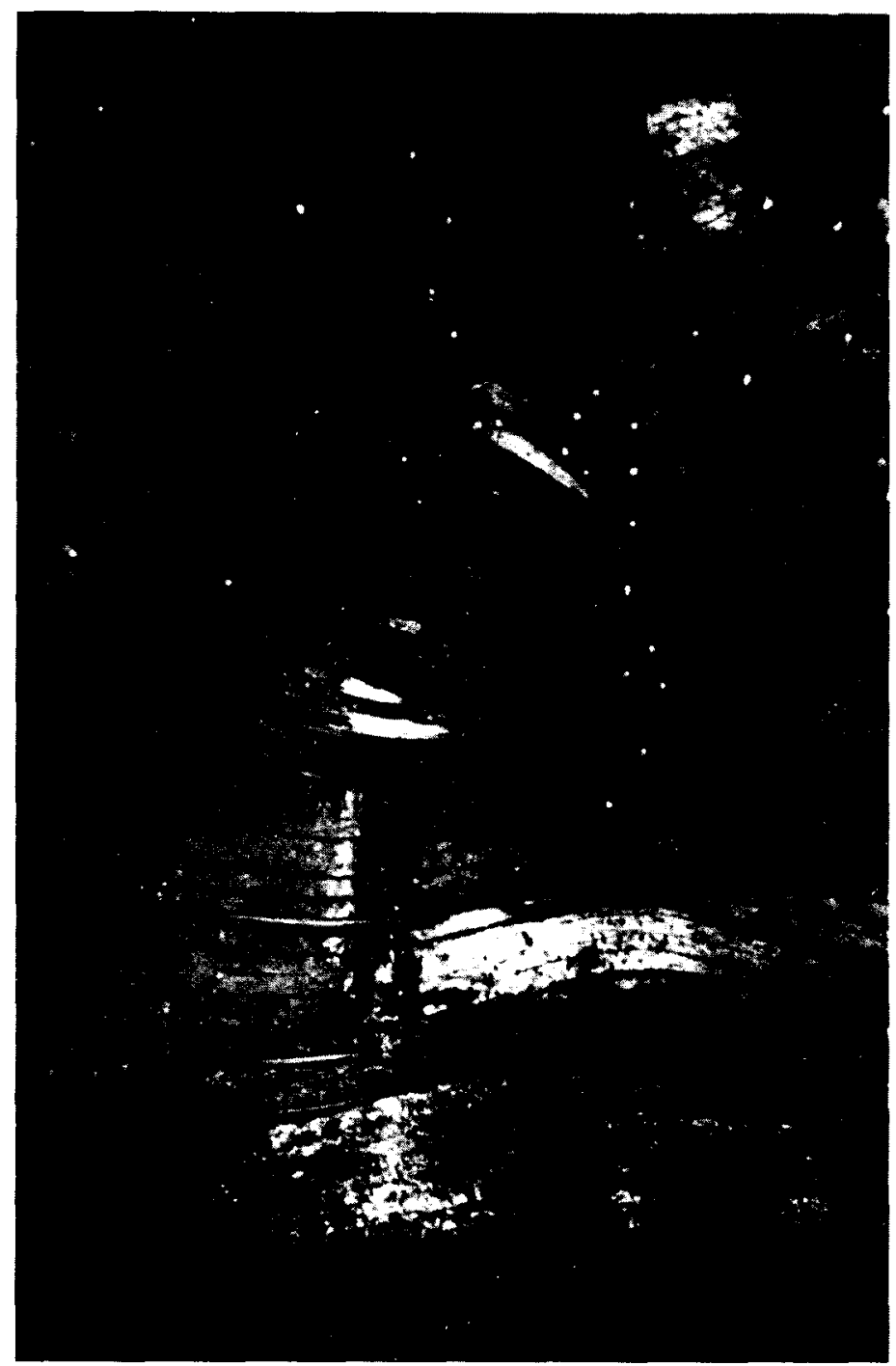

Fig. 17. Descubrimiento imprevisto, detalle posterior. 
verde se acentúa en el centro, donde un torso espera ser liberado de una materia que lo aprisiona. Pero al igual que en aquel bloque de piedra imaginado por Pedro García, el "hallazgo" de unos fósiles en el interior de la masa vítrea hará que el escultor tenga también que abandonar esta obra sin concluirla. Un detalle de la misma (fig. 17) resulta muy significativo para una mejor comprensión de la metamorfosis que se opera en las láminas de vidrio al ser sometidas a la acción del fuego. Éstas adoptan la apariencia sinuosa de unos estratos que han sido forzados por el empuje orogénico, cuya plasticidad es acentuada por la luz al resbalar por sus superficies irregulares.

En mi opinión, estas obras sintetizan lo que hasta el momento ha significado la actividad artística de Pedro García ${ }^{9}$, basada en la convicción del valor del vidrio laminado como material escultórico, capaz de generar volúmenes, formas nuevas en las que la luz se detiene para jugar con una materia que no busca la pureza y que se complace en lo irregular, en lo asimétrico, en el contraste de texturas y colores, y en aquello que evoca las erosiones naturales de la tierra. Pero también es el medio del que Pedro García se sirve para expresar su preocupación por una naturaleza que se va degradando día a día, y, por ello, intenta inmortalizar en el vidrio fragmentos de todo lo que pueda extinguirse en un futuro próximo, con la romántica idea de que este material milenario los proteja.

9 Pedro García es también el autor de la obra realizada en vidrio que decora "Mamá Carlota", antiguo "Bocaccio», inaugurado recientemente en Madrid. 
